


Subsídios para uma nova leitura biográfica de Amedeo Modigliani (1884-1920)

Autor(es): $\quad$ Poças, Susana Maria Loureiro Restier Grijó

Publicado por: Imprensa da Universidade de Coimbra

URL persistente:

URI:http://hdl.handle.net/10316.2/42450

DOI:

DOI:https://doi.org/10.14195/0870-8584_0_7

Accessed : $\quad$ 26-Apr-2023 12:03:57

A navegação consulta e descarregamento dos títulos inseridos nas Bibliotecas Digitais UC Digitalis, UC Pombalina e UC Impactum, pressupõem a aceitação plena e sem reservas dos Termos e Condições de Uso destas Bibliotecas Digitais, disponíveis em https://digitalis.uc.pt/pt-pt/termos.

Conforme exposto nos referidos Termos e Condições de Uso, o descarregamento de títulos de acesso restrito requer uma licença válida de autorização devendo o utilizador aceder ao(s) documento(s) a partir de um endereço de IP da instituição detentora da supramencionada licença.

Ao utilizador é apenas permitido o descarregamento para uso pessoal, pelo que o emprego do(s) título(s) descarregado(s) para outro fim, designadamente comercial, carece de autorização do respetivo autor ou editor da obra.

Na medida em que todas as obras da UC Digitalis se encontram protegidas pelo Código do Direito de Autor e Direitos Conexos e demais legislação aplicável, toda a cópia, parcial ou total, deste documento, nos casos em que é legalmente admitida, deverá conter ou fazer-se acompanhar por este aviso. 


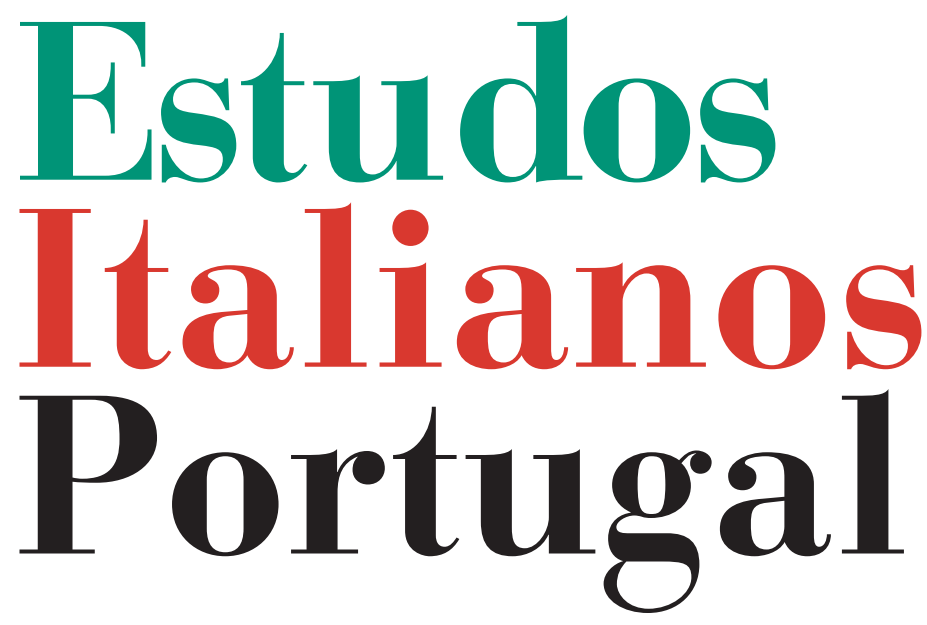

Instituto

Italiano

de Cultura

de Lisboa

Nova Série

$\mathrm{N}^{\mathbf{0}} \mathbf{0}$ 


\section{SUBSÍDIOS PARA UMA NOVA LEITURA BIOGRÁFICA DE AMEDEO MODIGLIANI (1884-1920)}

Susana Maria Loureiro Restier Grijó Poças

A pequena Cidade portuária de Livorno, com a infinita moldura marítima servindo-lhe de aspiração libertadora, assiste a 12 de Julho de 1884 à chegada do seu mais ilustre filho: Amedeo Clemente Garsin Modigliani.

A terra-natal do compositor Mascagni e do aclamado macchiaioli Giovanni Fattori, fôra o local eleito para acolher os dois ramos da Família Garsin-Modigliani. Os Garsin, estabelecidos em Livorno desde o século XVIII, mudam-se em 1835 e sob a égide de Giuseppe Garsin para Marselha, onde as tradições judaico-sefárdicas, de ascendências peninsulares, mantêm-se numa família numerosa que se congregara no $\mathrm{n}^{\mathrm{o}} 21$ da rue Bonaparte. A Regina Spinoza Garsin e ao seu filho Giuseppe, junta-se ainda o neto Isaac que vê nascer sete filhos do seu casamento com Regina Garsin: Evaristo, Alberto, Laura, Gabriella, Amedeo, Clementina e Eugenia. É num ambiente culto, marcado por especulações filosóficas e literárias, que cresce na jovem Eugenia uma personalidade forte e determinada. Em 1872, ao casar-se na sinagoga barroca de Livorno com Flaminio Modigliani, de confluente origem judaica, Eugenia faz regressar o nome dos Garsin à cidade de origem. Entre 1872 e 1884, a reservada casa no $\mathrm{n}^{\circ} 38$ da via Roma acolhe mais quatro novos membros: Giuseppe Emanuele nasce em 1872, Margherita Olimpia em 1874, Umberto Isacco em 1878 e finalmente Amedeo Clemente a 12 de Julho de 1884. 
O benjamim da família recebe apenas nomes dos Garsin: Amedeo como o seu tio, e Clemente em homenagem à sua tia Clementina, falecida em Maio desse ano. A infância do pequeno Amedeo, a quem chamavam pelo diminutivo de Dedo, decorre no $\mathrm{n}^{\circ} 4$ da via delle Ville, que os Garsin-Modigliani haviam ocupado pouco tempo após o seu nascimento e devido à falência que tornava austera a vivência diária do subitamente maioritário ramo materno.

A 17 de Maio de 1886, Eugenia inicia um diário sobre a vida da família, no qual aponta as primeiras impressões sobre o seu filho "um pouco mimado, um pouco caprichoso, mas joli comme un coeur." O precioso texto, possuidor de marcadas paragens cronológicas, permite constatar que Amedeo tornara-se o rebento favorito e, na ausência dos seus irmãos mais velhos, assumia-se como o centro das atenções num restrito universo de adultos. Nem mesmo a escola que Eugenia decidira abrir na sua própria casa em parceria com a irmã Laura e consequente presença diária de excedentes crianças conseguiu desvalorizar a precocidade de Amedeo, claramente derivada do convívio com os parentes.

Recebendo as primeiras lições em casa, sendo por isso adiado o seu ingresso escolar, Amedeo passa o seu tempo na companhia da tia Gabriella e sobretudo do avô Isaac, enquanto a sua mãe assumia, de forma invulgar nos padrões da sociedade de finais do século XIX, a chefia do clã. O velho patriarca, desiludido com as dificuldades monetárias e carregando o estigma de uma depressão nervosa, fôra em tempos um brilhante argumentador, jogador de xadrez e um homem particularmente culto. Leitor de história e filosofia dominava ainda várias línguas, como o italiano e o francês familiares, e também o espanhol, inglês, grego e um pouco de árabe. É na sua companhia que o pequeno Dedo passeia pelo porto de Livorno (no qual avistava-se longínqua a ilha da Córsega), crescendo gradualmente uma profunda admiração e amizade entre ambos. Ao único neto que o ouvia sedento de sabe- 
doria, Isaac abria as portas dos mundos da arte e da filosofia, deixando-lhe como herança uma vasta instrução, subitamente interrompida com a sua morte em 1894. Modigliani vê deste modo acrescidos os seus já invulgares e prematuros conhecimentos, sendo-lhe mesmo pontualmente atribuída a curiosa alcunha de "o filósofo".

Aos dez anos, Amedeo começa os estudos oficiais, frequentando o Ginnasio Guarrazzi de Livorno. Se obtém resultados escolares satisfatórios, Modigliani exterioriza os primeiros sinais preocupantes de uma saúde deficiente que, no verão de 1895, manifestam-se através de uma grave pleurisia. O diário materno regista o acontecimento, ao mesmo tempo que Eugenia evidencia a incerteza que ainda marca a personalidade do seu filho, inteligente, mas sempre mimado. Numa impressionante frase premonitória, a observadora mãe escreve que "mais tarde veremos o que existe nesta crisálida. Talvez um artista?" Um ano depois, ao pintar uma prateleira de temática simbolista com o seu amigo Uberto Mondolfi, Amedeo "confirma" as suspeitas de Eugenia que, em breve, serão drasticamente assumidas. Em 1897, Modigliani insere as suas classificações de estudante no jornal familiar, ao mesmo tempo que é admitido, aos treze anos, na comunidade judaica e balbucia o lápis em hesitantes desenhos.

O seguinte período afigura-se particularmente crucial para o desenvolvimento criativo do livornês. Assim, o ano de 1898 assiste a um repetido ataque de pleurisia acompanhada por febre tifóide que deixa o jovem Dedo em permanente delírio durante cerca de um mês. Conta-se, com alguma fantasia, que durante a fase crítica da doença, Modigliani teria revelado o seu desejo de se tornar artista enquanto referia nomes de quadros e pintores que desconhecia. Se o diário maternal omite a data da enfermidade, confirma a 17 de Julho o início previsto para o mês de Agosto das lições de desenho que Amedeo tanto ansiava. Desta forma, o jovem aspirante a artista inscreve-se no atelier de Guglielmo Micheli 
(1866-1926), discípulo do respeitado Giovanni Fattori (1825-1908), situado no rés-do-chão da Villa Baciocchi. Enquanto recebe os ensinamentos no atelier de Micheli, frequentemente visitado pelo professor Fattori que observava atentamente os esforços do recente aprendiz, Amedeo desiste dos estudos liceais entre 1898-99.

Segundo as palavras escritas de Eugenia, Modigliani dedicava-se totalmente à pintura e ao desenho com um empenho que a figura materna desconhecia, a par de variadas leituras que incluíam as obras de F. Nietzsche, Henri Bergson, Baudelaire, Lautréamont, Verlaine, Oscar Wilde, Dante, Shelley, Kropotkine... A sua preferência por Nietzsche permite mesmo que no estúdio de Guglielmo receba, em substituição de "o filósofo", o apelido de "super-homem". Alternando as lições de arte com a frequência do célebre Café Bardi situado na Piazza Cavour, o italiano lentamente integra-se no grupo orientado por Micheli, no qual contavam-se, entre outros, Gino Romiti (1881-1967), Renato Natali (1883-1979), Llewelyn Lloyd (1879-1949), Aristide Sommati (1881-1970), Benvenutu Benvenuti (1881-1959), Manlio Martinelli (1884-1974), Lando Bartoli e Oscar Ghiglia (1876-1945), todos eles consideravelmente mais velhos que o avançado colega. Podemos imaginar as longas tertúlias, a partilha de visões artísticas, os debates literários e até mesmo os passeios pelas redondezas campestres onde ensaiavam novos temas pictóricos.

Mas o convívio e desejado trabalho de Modigliani são subitamente interrompidos pela violenta manifestação de uma lesão pulmonar derivada da febre tifóide ocorrida dois anos antes. Em finais de 1900, um surto de tuberculose prenuncia o diagnóstico clínico que não contempla esperança para o jovem de dezasseis anos, cuja morte era aguardada para breve. A Eugenia é requerida a inevitável resignação, mas a corajosa mãe, de imparável força interior, decide assumir uma derradeira tentativa para salvar o seu filho mais novo. Com o apoio financeiro de Amedeo Garsin, mãe e filho 
deixam para trás não só o ambiente húmido e prejudicial de Livorno como, surpreendentemente, toda a família Garsin-Modigliani, rumo às cidades de Nápoles, Capri, Amalfi, Roma, Florença e Veneza. Para a genealogia do artista, no ressurgir de vozes e influências, a transição de 1900 para 1901, reveste-se de especial alcance. Sempre acompanhado pela mãe, Amedeo convalesce gradualmente, enquanto visita as glórias artísticas dos locais por onde vai passando, radicalmente distintos da pacata Livorno, e repletos de igrejas, museus e agitadas populações.

O estímulo que este imprevisto processo de aprendizagem provoca encontra-se bastante evidente nas cartas que Modigliani escreverá a Oscar Ghiglia. Redigidas na transição dos dezasseis para os dezassete anos, as missivas evidenciam a promessa de um futuro maior, de uma alma que queria crescer cada vez mais para "salvar o seu sonho". Se é certo que essas cartas, escritas em pleno final da adolescência, estão imbuídas de um marcado idealismo romântico herdado do fin-de-siècle, constituem identicamente impressionantes "monumentos literários à maneira de D'Annunzio."

Em 1902, o regresso à cidade de origem revela-se fugaz pois Modigliani, de saúde restabelecida, depressa muda-se para Pietrasanta, perto de Carrara, onde experimenta as primeiras incursões na escultura. Da ancestral nascente do mármore o livornês transita para Florença, inscrevendo-se a na Scuola Libera del Nudo da Academia de Belas-Artes, com a intenção de assistir às aulas de Giovanni Fattori. Dividindo um atelier com o amigo Ghiglia, Amedeo claramente seguira a perene admiração sentida pelo velho macchiaioli, na escolha de Florença como local para o seguimento da clássica formação artística. Pouco chegou até nós dos meses passados sob a égide de Fattori e do convívio com Oscar, mas a futura mudança para Veneza é atribuída não só à aguardada insatisfação em face das lições na Academia, como ainda à transformação da vida do seu amigo. 
Assim, a 19 de Março de 1903, Modigliani regista no boletim de inscrição a sua integração na repetente Scuola Libera del Nudo do Real Instituto de Belas-Artes de Veneza, regressando deste modo à cidade que antes exercera um marcado fascínio no estudante. O suporte financeiro do seu tio Amedeo Garsin permite a instalação na burguesa via 22 Marzo, mas a impossibilidade de prosseguir com o capricho depressa provoca a transferência sucessiva para as zonas de San Sebastiano e Campiello Centopiere. Por entre a parca frequência do Instituto e as numerosas visitas aos monumentos venezianos, o jovem italiano conhece, entre outros, Umberto Boccioni, Ardengo Soffici, Guido Cadorin, Fabio Mauroner e especialmente, Manuel Ortiz de Zárate.

É Ortiz que introduz Amedeo às vanguardas parisienses, não só através da partilha de experiências que absorvera na sua passagem pela capital francesa, mas também nas visitas que ambos fazem às Bienais de Veneza. No ano de 1905, o caminho veneziano de Modigliani sofre um duro golpe com a morte de Amedeo Garsin em Marselha. Ao brusco término do apoio financeiro do tio vem juntar-se o crescente desejo de partir rumo a Paris, agora que a lição italiana "reclamava" a distância necessária para verdadeiramente ganhar forma. As insistências junto da mãe permitem que a viagem para França se transforme em realidade e, nos finais do ano, Eugenia visita o filho em Veneza.

O belo toscano, de fronte altiva e aristocráticas vestes, levando na bagagem livros, postais e uma carta de recomendação de Ortiz de Zárate, vislumbra pela primeira vez, na invernosa alvorada de 1906, a cidade dos Boulevards de Haussmann, do venerado Louvre e da emocionante Torre Eiffel. Apresentando-se então como escultor, Modigliani inscreve-se na Academia Colarossi, situada na rue de la Grande- Chaumière. Financeiramente incapaz de manter o elevado e burguês estilo de vida inicial, o italiano vê-se forçado a abandonar Montparnasse, encontrando abrigo no popular Maquis 
situado na rue Caulaincourt, em Montmartre. Enquanto admira as obras dos Fauves, Modigliani expõe no final do ano três obras na Art Gallery de Laura Wylda. Entre 1906 e 1908, o livornês mudará com frequência de morada, passando pelo Hôtel du Tertre, Hôtel du Poirier e pelo incontornável Bateau-Lavoir, enquanto continuava a receber de Itália o esforçado apoio familiar. Na passagem de 1906 para 1907, Modigliani ilustra um pequeno livro de desenhos cuja frente e verso possuem peculiares figurações, e no qual surgem não só um soberbo auto-retrato, como ainda a notável frase: "O que eu procuro não é o real nem o irreal, mas o Inconsciente o mistério do que é Instintivo à Raça."

Algumas das criações deste tempo são apresentadas ao público no Salon d'Automne de 1907, onde Amedeo está representado através de dois óleos e cinco aguarelas. Os quadros desses anos apresentam um cromatismo sombrio, com decadentes figuras que elevam-se das sombras por entre expressões dolorosas em corpos violentamente delineados, feitos em simultâneo com vigorosos desenhos. Estudando na Academia Ranson, o artista não só treina o tema do nu, como realiza alguns dos seus primeiros apontamentos de espectáculos a que assistia, nomeadamente, no auditório do Teatro Gaîté-Rochechouart. Para esta gradual consolidação contribuiu certamente a sua passagem pelo Bateau-Lavoir, local que acolhia um diversificado grupo de colegas seus.

Sob a batuta da americana Gertrude Stein, diversos artistas, poetas e escritores reuniam-se para debater, em ardentes e concorridas tertúlias, os revolucionários caminhos que desejavam abrir no recém-chegado século. Terá sido num desses encontros que Amedeo conheceu o seu homónimo português, Amadeu de Sousa Cardoso (1887-1918), nascendo talvez aí a grande amizade e simpatia que fortemente os uniu.

Enquanto suporta os primeiros momentos de dificuldades materiais derivados, numa fase inicial, do processo de busca de um estilo e sequente adiamento da completa inte- 
gração no mercado dos marchands, o livornês muda-se em Abril para o n ${ }^{\circ} 14$ da Cité Falguière. Em 1909, o persistente trabalho de pintura e desenho de Amedeo é alternado com as visitas que faz aos Salons (admirando as obras dos cubistas), enquanto habita em distintas zonas da metrópole, como na rue Boissonade, no $\mathrm{n}^{\mathrm{o}} 7$ da Place Jean-Baptiste-Clément ou na circular e babilónica La Ruche. É nesta última que Laura Garsin confronta-se com as dificuldades vivenciais do sobrinho que, se certamente experimentava pontuais momentos de boémia (que a lenda irá desfigurar), debatia-se diariamente com a marca de uma doença que de forma lenta ia seguindo o seu curso.

Deixando transparecer a fadiga e magra subsistência quotidianas, Modigliani, três anos depois da mudança para $\mathrm{Pa}-$ ris, regressa a Itália em Julho de 1909. Durante os meses de repouso, o italiano pinta retratos, frequenta o estúdio de Gino Romiti e visita as cidades de Pisa e Siena, enquanto convive com a saudosa família.

A chegada a França acontece em finais de Setembro, onde o recuperado e confiante artista renova os contactos e prossegue o trabalho. No sequente ano, Modigliani, transpondo para a pedra as sinuosas figuras que desenhava, apresenta no XXVI Salon des Indépendants alguns dos óleos que realizara em Livorno. Por esta altura, a partilha de experiências entre Amedeo e o nosso Amadeu de Sousa Cardoso espelhavam-se na magnífica abordagem gráfica do português.

A transição de 1910 para os meses inaugurais de 1911 traz consigo um voluntário acréscimo de trabalho, pois Modigliani e Sousa Cardoso escrupulosamente preparavam uma investida artística em parceria. Os dois Amadeus, imbuídos de uma mútua admiração alicerçada numa forte amizade, esmeravam-se na organização da mostra conjunta que inauguraram a 5 de Março de 1911 no faustoso atelier do português situado no $\mathrm{n}^{\mathrm{o}} 3$ da rue $d u$ Colonel Combes. Da exibição não foram ainda localizadas fotografias, convites ou o catá- 
logo que certamente a completou, contudo é sabido que Modigliani arriscou uma pré-apresentação de um original ensemble de sete esculturas, a par de guaches representando graciosas cariátides; enquanto Sousa Cardoso expôs inventivos desenhos e coloridas aguarelas. Se o resultado esperado da iniciativa esteve aquém das expectativas, pois não passou de uma celebração particular sem conhecido impacto na crítica ou no mercado dos marchands durante a sua desconhecida duração, alcançou contudo uma fulcral importância não só enquanto testemunho de uma amizade única, mas pelo decisivo impulso para o avanço das carreiras de ambos.

Assim, tanto Amedeo como Amadeu insistem com os seus projectos, de convergência que nunca incorreu num decadente mimetismo, enquanto conviviam com os restantes camaradas lusos. Se o amarantino integra o XXVII Salon des Indépendants, o seu amigo livornês declina a oportunidade em primazia da prática da escultura, arrojadamente realizada em talha directa, implicando um prodigioso esforço físico.

Confrontado com as dúvidas criativas, que acresciam as já salientes atribulações diárias numa escassez de suportáveis condições existenciais, Amedeo decide aceitar a proposta que Laura Garsin desesperadamente faz ao sobrinho para uma digressão pelas supostamente saudáveis e veraneantes terras da Normandia. Antes porém de ir ao encontro da tia, o livornês antecipa uma visita a Fécamp e, ao chegar ao acordado destino de Yport, envia um postal ao seu amigo Amadeu de Sousa Cardoso. É em Amarante que Amadeu recebe a 18 de Setembro a imagem das falésias de Yport, acompanhada de uma palavra de lembrança que vincava o inexistente esmorecimento de uma amizade, pois o italiano, sem precisar de estender-se em monótonas e banais descrições turísticas, assina unicamente o seu cadenciado sobrenome: Modigliani.

No findar do emblemático ano de 1911, uma preciosa hermafrodita pintada em Novembro por Amedeo torna-o 
especialmente relevante, já que o italiano decide oferecê-la a Sousa Cardoso, como confirmação da sua estima.

Transcorrido quase um ano, entre 1 de Outubro e 8 de Novembro de 1912, tem lugar no magnificente Grand Palais o X Salon d'Automne que incluía a insólita Sala XI, imortalizada como a Sala dos Cubistas e na qual estavam integradas quatro esculturas de Modigliani. A única imagem da disputada sala permite-nos um vislumbre de uma parte integrante do que seria a edificação templária que o toscano vagarosamente tentava erigir. Pouco depois, no final do ano, Amedeo muda-se para o no 39 da Passage de l'Elysée des Beaux-Arts em Montmartre. São alguns dos artistas que então privavam com o livornês que assistem ao acelerado esgotamento físico do amigo que, alcança proporções alarmantes quando este é encontrado desvanecido no atelier. Com a ajuda dos amigos, Modigliani consegue juntar a quantia suficiente para viajar até Livorno, com o intuito de restaurar a sua enfraquecida saúde. De lá voltará restabelecido, mas sem poder prever que jamais voltaria a Itália.

Modigliani, enquanto usufruia da protecção do marchand Chéron, ruma para o n 216 do cêntrico Boulevard Raspail. $\mathrm{O}$ ano de 1914, que começara com uma instabilidade europeia que prenunciava a eclosão do primeiro conflito bélico do século, provoca inúmeras e inesperadas metamorfoses no meio artístico parisiense. As grandes celebrações findavam, as reuniões nos cafés ameaçavam tornar-se raras e desertas e, por entre a preocupação de um futuro que se anunciava incerto, o italiano é apresentado a um novo marchand - Paul Guillaume -; e a uma jornalista inglesa de 35 anos, de seu nome Beatrice Hastings. Entre 8 de Maio e 20 de Junho, o livornês integra a secção judaica da mostra Twentieth Century Art que acontece na Whitechapel Gallery de Londres.

Assistindo com 30 anos ao rebentar da Primeira Guerra Mundial, Modigliani presencia também o regresso massivo dos amigos portugueses ao país natal, bem como a mobiliza- 
ção dos seus parceiros. Enquanto partilhava a sua existência com Beatrice Hastings, Amedeo mudou frequentemente de estúdio, habitando sucessivamente no $\mathrm{n}^{\circ} 16$ da rue de Saint-Gothard, no $\mathrm{n}^{\mathrm{o}} 13$ da rue Ravignan e no $\mathrm{n}^{\mathrm{o}} 53$ da rue $d u$ Montparnasse. O ambiente dramático da Primeira Grande Guerra acentua-se em 1915, ano em que Modigliani abandona definitivamente a escultura. Em Dezembro, o artista participa numa exposição colectiva, organizada por Amédée Ozenfant, e na qual estão também presentes Picasso, Kisling, Léger e Derain. Passados cerca de sete meses, entre 16 e 31 de Julho de 1916, Modigliani integra o célebre Salon d'Antin, organizado por André Salmon. Enquanto convive com os maiores nomes da arte e da literatura da época, Amedeo separa-se, entre Julho e Agosto, de Beatrice, após dois anos de uma tempestuosa ligação.

A sua produção artística desperta um desmedido fascínio num moço poeta polaco chamado Léopold Zborowski, admirador do talento do italiano desde 1915. Esse talento, assente numa profunda postura meditativa, recebeu um entusiasmado aplauso aquando da exibição Lyre et Palette, que esteve aberta ao público entre 19 de Novembro e 5 de Dezembro. É no apartamento de Zborowski, situado no $\mathrm{n}^{\mathrm{o}} 3$ da rue Joseph-Bara, que Modigliani prossegue a sua luta no ano de 1917. Partilhando o mesmo espaço com Kisling e Soutine, o livornês traça alguns dos seus mais esplendorosos retratos e avança com a gloriosa série de nus.

Enquanto pintava, a um vertiginoso ritmo, Amedeo frequentava pontualmente a Academia Colarossi, onde estudava uma jovem artista de enigmáticos olhos verdes chamada Jeanne Hébuterne. Quando Modigliani a conhece, na Primavera de 1917, Jeanne tem 19 anos e a sua grande ambição é tornar-se pintora. Durante alguns meses a ligação ao italiano judeu foi ocultada à Família Hébuterne mas, em Julho, Jeanne corajosamente abandona o meio seguro e confortável da casa dos seus pais rumo a um decadente atelier que o apoiante 
Zborowski alugara para o decidido casal no $\mathrm{n}^{\circ} 8$ da rue de la Grande-Chaumière.

Com entusiasmo, e enquanto transpõe para a tela as faces dos que o rodeavam, o italiano participa na exposição da Galeria Dada em Zurique, unindo-se à atitude anti-belicista do grupo dadaísta. A produção de 1917 apresenta-se para Zborowski como possuidora de uma coerência de contemplativas e invulgares qualidades, e o marchand decide partilhá-las com o público das galerias promovendo, juntamente com Berthe Weill, a primeira exposição individual de Modigliani, que fechará as suas portas no próprio dia da sua abertura.

Tolerando cada vez menos os sucessivos ataques a Paris, Amedeo exterioriza sinais de um preocupante agravamento do seu estado de saúde. Zborowski opta por levá-lo para Nice, acalentando escapar aos constantes bombardeamentos e restaurar, num ambiente saudável, a robustez do seu protegido. Em Março de 1918 e rumo ao sul de França vão Léopold, Hanka Zborowski, Modigliani e Jeanne. Primeiramente habitando na rue Masséna, Modigliani muda-se para os $n^{\text {os }} 5$ (Hotel Tarelli) e 13 da rue de France.

É em Nice que Modigliani recebe uma dolorosa notícia: o seu amigo Amadeu de Sousa Cardoso, regressado a Portugal pouco antes do começo da guerra, sucumbira, a 25 de Outubro e com apenas 30 anos, à devastadora pneumónica.

Um mês depois, Jeanne anuncia uma nova vida ao tumultuoso mundo que a rodeava. Na sexta-feira de 29 de Novembro de 1918 nasce na Maternidade de Nice, Jeanne Modigliani, cujo nome eterniza os dos seus pais: Jeanne Hébuterne e Amedeo Modigliani. Antes do final do ano, entre 15 e 23 de Dezembro, Paul Guillaume junta, numa mostra intitulada Les peintres d'aujourd'hui, obras de Modigliani, Picasso, Matisse, Utrillo, Chirico e La Fresnaye, expostas na sua galeria em Paris. Na passagem de 1918 para 1919, uma carta de Amedeo para Zborowski deixa constatar a esperança que a 
pequena filha tinha trazido ao artista que, no fim da missiva, escreve: "Resurrectio Vitae. Ic incipit vita nova".

Amedeo habitava agora na casa de Anders e Rachel Osterlind, situada no chemin des Colletes em Cagnes. Enquanto convivia com o casal Osterlind o italiano escreve à sua mãe, contando os progressos da filha Giovanna como, em bom italiano, a chamava. Talvez tentando ultrapassar a angústia que o assolava, Modigliani experimenta uma temática inédita em toda a sua produção, pintando as suas únicas paisagens.

O seu talento chegara mesmo ao conhecimento de um velho e venerado mestre que, em Cagnes, dolorosamente pintava os seus últimos quadros: Renoir. Por intermédio de Osterlind, Renoir aceita receber o italiano, sobre o qual ouvira dizer o elogio de ser um grande pintor. Conta-se que o encontro correu mal, pois Modigliani não podia compreender o apego do pintor às formas e características dos seus modelos, manifestamente corpóreas, quando a sua busca era a da alma, do que está subjacente à realidade fisica e material. Desesperado, o livornês planeia um iminente retorno a Paris. A guerra havia já terminado e Modigliani não encontrara no sul de França a recuperação e tranquilidade esperadas.

A 31 de Maio de 1919, Amedeo finalmente regressa à capital. Um mês depois, Jeanne Hébuterne e a filha de ambos juntam-se a Modigliani no atelier da rue de la Grande-Chaumière. Em Agosto, o imparável marchand, em parceria com os irmãos Osbert e Sacheverell Sitwell, apresenta obras de Amedeo na mostra Modern French Art que decorreu na Mansard Gallery de Londres. Modigliani, célebre e respeitado, vivia a exaltação do reconhecimento, mas essa mudança não alterou a sua postura vivencial que nunca contemplou uma visão mercenária da sua arte. Para além de jamais ter recorrido a um emprego para vencer as graves dificuldades financeiras que consumiram a sua vida, o livornês nunca subiu o preço das suas obras, continuando a cobrar cinco francos por desenho, mesmo quando os compradores lhe ofereciam 
o dobro do valor estabelecido. À participação na exposição londrina segue-se o retorno aos Salons, mostrando quatro pinturas no Salon d'Automne, enquanto realizava alguns dos seus derradeiros, mas soberbos retratos.

Durante o árduo Inverno, o artista planeia passar um período em Itália, fazendo novos projectos para si e para sua jovem família que brevemente esperava receber um novo membro. Contudo, a ausência de condições materiais que pudessem adiar o inevitável, faz manifestar violentamente a tuberculose de que sofria. Entre os finais de 1919 e inícios de 1920, Modigliani confronta-se com a última investida da chaga que o minava. Os dias terminais do artista são passados entre a criação de desenhos e alguns óleos. A morte sabia-a estar próxima, pois a doença que firmemente suportara desde a adolescência estava prestes a finalizar o seu percurso. No domingo de 18 de Janeiro de 1920, Amedeo adoece gravemente e quatro dias depois é levado inconsciente para o Hospital da Charité. Jeanne, numa silenciosa dor, permanecera imóvel ao seu lado, sabendo que a luta contra a "hecatombe” da humanidade seria inútil. A 24 de Janeiro de 1920, sem nunca ter recuperado a consciência, morre com 35 anos, Amedeo Clemente Garsin Modigliani, vítima de meningite tuberculosa.

No dia seguinte, observada pelo pai, Jeanne despede-se de Modigliani e retorna à casa-natal, enquanto o Dr. Barrieu, Moricand, Kisling e Lipchitz tentavam realizar uma máscara mortuária do amigo. Antevendo o desespero interior da irmã, com uma filha orfã e na iminência de ser novamente mãe, André Hébuterne leva parte da noite a vigiar Jeanne. Num momento de ausência de André, Jeanne Hébuterne atira-se, na alvorada de 26 de Janeiro, do quinto andar do $\mathrm{n}^{\circ}$ 8, bis da rue Amyot. Grávida de nove meses, a coerente jovem de 21 anos sofreu morte imediata e deixou para trás a pequena Jeanne, de quase 14 meses de idade. Emanuele Modigliani, avisado da morte do irmão, envia 
um telegrama pedindo a Zborowski que cobrissem Amedeo de flores e a Família, desconhecendo o suicídio de Jeanne, convida-a a viajar até Florença (para onde os Modigliani haviam mudado) com a filha.

O imponente funeral de Modigliani, organizado por Kisling que decidira enterrá-lo no cemitério dos mais ilustres artistas e escritores, sai do Hospital rumo ao infindável Père-Lachaise, atravessando a cidade onde vivera a quase totalidade da sua vida de adulto e na qual tivera a imperiosa distância para elaborar a sua obra. A acompanhar a última viagem do livornês encontrava-se uma multidão de artistas, chocados com o fim de uma juvenil e promissora vida.

No dia 28, os pais de Jeanne levam-na para um sombrio cemitério do subúrbio de Bagneux, não permitindo a presença dos amigos do casal; enquanto Jeanne Modigliani, alheia à drástica mudança vivencial de que fôra alvo, é encaminhada para Itália, sendo prontamente adoptada pela sua tia Margherita, em face da recusa de acolhimento por parte da Família Hébuterne.

Deste modo, mediante uma abrupta morte, findava o caminho da notável "evolução criadora” de Amedeo Modigliani, artista que ao chegar em 1906 à centralizadora capital das artes, criou uma obra que começou por uma busca potencial de um rosto universalista e agregador; passou pelo sonho de uma edificação celebrante da fusão entre o tempo antigo e o tempo moderno; sobreviveu à verdade dramática de um conflito mundial através de uma pintura catártica e lírica; culminando num corpo coerente que não teve mestres nem deixou discípulos, que não ambicionou propôr modelos, mas defendeu a recuperação memorizante de um legado ancestral, sem visões miméticas ou revivalistas, reencontrando-o com uma arte contemporânea à vivência do artista, cristalizando uma atemporal historicidade pelo diálogo entre o venerado passado e a presente esperança de um futuro que o integrasse. 
Hoje, passados oitenta e cinco anos da sua morte, que Modigliani é celebrizado como o inefável "Príncipe de Montparnasse", o "pintor maldito" ou o "último dos boémios", torna-se cada vez mais urgente olhar a incomparável obra para a partir dela descobrir um artífice cujo nome adquiriu, no panteão da arte do século XX, a glória da individualidade, alheia a movimentos ou teorias, modas ou ideologias, e que através de uma tipologia figurativa inigualável, manifestamente mostrou como a modernidade deve conter sempre a identidade.

$\mathrm{Na}$ remota lembrança que nos unifica, Amedeo Modigliani, o livornês que precisou de partir rumo a Paris para criar uma arte intrinsecamente italiana, alcançou o estatuto de uma admirada figura de culto por, em último grau e superando o mito que o duplica, nunca ter deixado de ser igual a si próprio e pela emocionante "homenagem que prestou à existência humana”. ${ }^{1}$

1 O presente artigo constitui um vincado resumo do sub-capítulo 1.1. do Capítulo I da nossa dissertação de Mestrado em História da Arte, pelo que foram omitidas todas as notas, bem como as imagens correspondentes.

Para uma leitura integral e completa não só do texto agora apresentado, como da nossa investigação sobre Amedeo Modigliani, presentemente a ser desenvolvida para uma dissertação de Doutoramento em História da Arte, por favor consultar:

(C) Susana Maria Loureiro Restier Grijó Poças - AMEDEO MODIGLIANIO preciosismo do desenho e as cumplicidades lusas. 1884-1920. Porto - Portugal: Dissertação de Mestrado em História da Arte, Faculdade de Letras da Universidade do Porto, 4 Volumes, 1000 pp., 1998. (Todos os direitos reservados). 